\section{An unusual presentation of stridor in an infant}

A 9-month-old boy presented with a 1-day history of fever and croupy cough. He had been diagnosed with laryngomalacia at 4 months of age and treated for recurrent croup and bronchiolitis. He was $<0.4$ th centile for weight.

He had marked biphasic stridor in all positions along with tachypnoea. He showed some initial improvement with bronchodilators, steroids and antibiotics for suspected pneumonia, but his stridor persisted. He decompensated after 2 days of treatment.

Emergency intubation was performed in theatre followed by microlaryngoscopy. Figure 1 shows the findings of extensive laryngeal papillomatosis around the endotracheal tube. The child was transferred to a tertiary ear, nose and throat unit where he had microlaryngobronchoscopy and removal of papillomas, with intralesional cidofovir injections. He is now doing well.

This case highlights the importance of defining the quality of stridor and using this to formulate differential diagnoses. ${ }^{1-3}$

Laryngeal papillomatosis is a benign growth of the epithelium of the larynx, trachea and bronchi caused by human papilloma virus types 6 and 11. The Gardasil vaccine may be used preventatively in mothers and potentially curatively in children. ${ }^{4}$

Laryngeal papillomatosis is rare (incidence of 1-4 cases per 100000 population $^{6}$ ), but due to its morbidity ${ }^{1-3}$ it must always

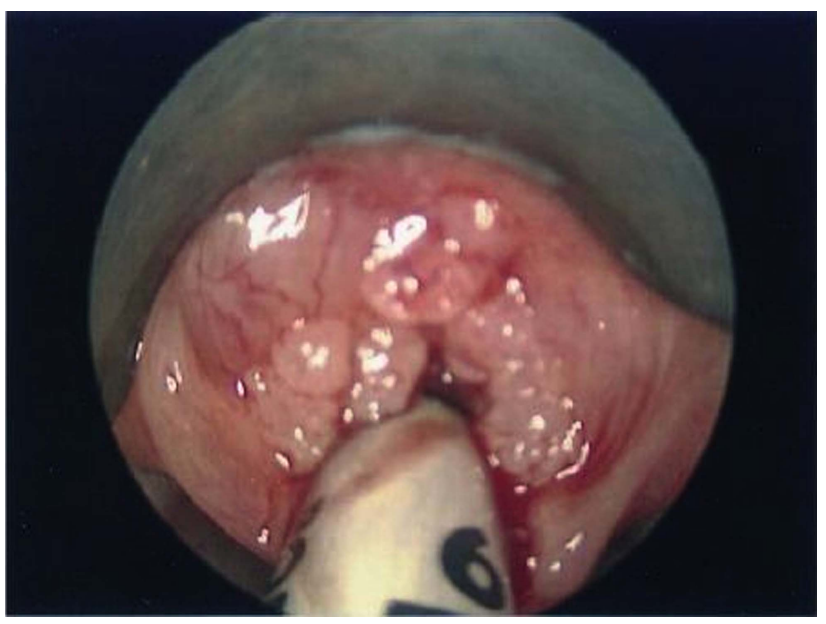

Figure 1 Microlaryngoscopic view of laryngeal papillomas. be included in the differential diagnosis of recurrent paediatric stridor with the following red flags: ${ }^{1-3} 78$

- stridor at rest

- progressively worsening stridor over time

- abnormal cry

- severe respiratory distress (cyanosis with laryngomalacia is rare)

- biphasic/expiratory stridor

- failure to thrive

- hoarse voice/dysphonia/aphonia.

Arindam Das, ${ }^{1}$ Jessica Bewick, ${ }^{2}$ John Chapman, ${ }^{1}$ Nuwan Siriwarnasinghe, ${ }^{1}$ Oluseun Tayo, ${ }^{1}$ Maria Giakoumi ${ }^{1}$

'Department of Paediatrics, James Paget University Hospital, Gorleston, Great Yarmouth, UK

${ }^{2}$ Department of ENT, James Paget University Hospital, Gorleston, Great Yarmouth, UK

Correspondence to Dr Arindam Das, Department of Paediatrics, James Paget University Hospital, Gorleston, Great Yarmouth NR31 6LA, UK; drdasa@gmail.com

Contributors $A D$ is the main author. Both $\mathrm{JB}$ and $\mathrm{OT}$ edited the article prior to submission. Images contributed by NS and MG. JC is the consultant clinician responsible for the care of this patient and provided the details of the clinical history.

Competing interests None.

Patient consent Obtained.

Provenance and peer review Not commissioned; externally peer reviewed.

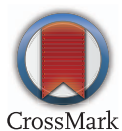

To cite Das A, Bewick J, Chapman J, et al. Arch Dis Child 2015;100:599.

Accepted 27 November 2014

Published Online First 19 December 2014

Arch Dis Child 2015;100:599. doi:10.1136/archdischild-2014-307025

\section{REFERENCES}

1 Goon P, Sonnex C, Jani P, et al. Recurrent respiratory papillomatosis: an overview of current thinking and treatment. Eur Arch Otorhinolaryngol 2008;265: 147-51.

2 Bjornson CL, Johnson DW. Croup. Lancet 2008;371:329-39.

3 Fasunla AJ, Lasisi OA. Diagnostic challenges of laryngeal papillomatosis and its implications among children in developing country. Int J Pediatr Otorhinolaryngol 2009:73:593-5.

4 Shah KV. A case for immunization of human papillomavirus (HPV) 6/11-infected pregnant women with the quadrivalent HPV vaccine to prevent juvenile-onset laryngeal papilloma. J Infect Dis 2014;209:1307-9.

5 Mudry P, Vavrina M, Mazanek $P$, et al. Recurrent laryngeal papillomatosis: successful treatment with human papillomavirus vaccination. Arch Dis Child 2011;96:476-7.

6 Larson DA, Derkay CS. Epidemiology of recurrent respiratory papillomatosis. APMIS 2010;118:450-4.

7 Harris AT, Atkinson $H$, Vaughan $C$, et al. Presentation of laryngeal papilloma in childhood: the Leeds experience. Int J Clin Pract 2012;66:183-4.

8 Coope G, Connett G. Juvenile laryngeal papillomatosis. Prim Care Respir J 2006:15:125-7. 